\title{
First, do no harm
}

\author{
Scott Groudine and Philip D Lumb Albany Medical College, Albany, New York, USA
}

\begin{abstract}
When a physician acts as both doctor and researcher conflicts can develop. When a doctor does not know whether a patient is taking active drug or placebo, any new medical problems can result in a dilemma. Is the patient's suffering a side effect of the medication or is this a new medical problem? Mrs W's case demonstrates the problem that can occur when the physician is blinded in the name of research.
\end{abstract}

\section{First, do no harm}

The quotation, "First, do no harm" (Primun non nocere) is old enough to be attributed to both Galen and Hipprocrates. Medical science has changed significantly since then. Many patients now are living with untreatable diseases that inevitably cause death and severe pain. Patients with terminal diseases often turn to untested experimental treatments when current therapies offer them little hope of survival or relief. Doing nothing, in these situations, results in certain harm. For this reason we agreed to participate in a clinical research trial of a new medication, which when given via a catheter inserted directly into the spinal cord fluid may eliminate cancer pain which is refractory to all other conventional treatments.

This trial was to last ten days. In return for the hope of pain relief, patients were expected to remain hospitalized and allow frequent monitoring of their pain, physiology and psychological state. Three patients eagerly and immediately enrolled in the study. One of these patients, Mrs W, had complications which caused us to be concerned about the ethics of continuing with this research protocol.

Mrs W is a 74-year-old woman with constant back pain from cancer which had spread to her bones. Opioids cause Mrs W severe gastrointestinal problems. She takes only minimal amounts and was resigned to live the rest of her life in pain. When her family doctor told her about our study she was eager to travel the $250 \mathrm{~km}$ to our medical centre to participate.

The study design called for some patients to get

\section{Key words}

Ethics; research; blinding; complications; paraplegia. active drug for five days and others to get placebo. After five days those patients that did not get pain relief would be switched to the other medication. Those experiencing pain relief would be allowed to continue on the same medication for the rest of the study and beyond. This was a placebo-controlled, double blind, crossover study with only the pharmacist who prepared the medication knowing who was getting placebo or study drug.

We placed a catheter into Mrs W spinal canal so that medication could be delivered directly to the spinal cord. On day three of the trial, Mrs W had some pain relief but also was complaining of right leg weakness and difficulty with urination. She now needed a walker to ambulate. This was of great concern to us because these problems could have been caused by the catheter that had been inserted in the spinal space. If not treated promptly permanent paraplegia and loss of bladder function could develop. However, her pain was getting better and that suggested the possibility that she was receiving an active medication. We spoke to the manufacturer of the drug and were told that Mrs W's symptoms had been reported with the use of this drug previously and were transient in nature. We were reminded that breaking the blind and removing the catheter would result in removal of Mrs W from the study. This drug was relieving her pain while making it transiently more difficult for her to walk; but what if she was getting placebo? The stakes were high. A wrong guess could result in paraplegia or a lifetime of pain for Mrs W. Breaking the blind for a temporary drug effect would have wasted Mrs W's time and travel while taking away the opportunity to use an effective pain therapy for the remainder of her life. If we let the study proceed we could be responsible for Mrs W becoming a paraplegic in addition to her other problems.

A wrong decision could hurt this patient. While we agonized over the options it became apparent that there was someone who did know what to do. The pharmacist knew what Mrs W was getting and if it was placebo, every minute delayed could be harmful. Our medical ability to care for this patient was impaired because we were blinded to important medical information. 
While debating the risks and benefits of continued study involvement with Mrs $\mathrm{W}$ and her family, Mrs W related that her right leg now could not move at all. We immediately terminated Mrs W's participation in the study on her third day of the trial. The spinal catheter was removed, the blind broken and a neurosurgeon urgently consulted. Mrs W was receiving active medication through her catheter which caused most of her symptoms. She also was found to have a metastasis of her cancer impinging on her spine, which caused the right leg paralysis. Emergency radiation treatments palliated this problem.

We stopped participating in this study because the side effects of the drug overlap the potential complications of a spinal catheter. The possibility of ascribing symptoms to a drug (that may not even have been administered to a patient) and overlook $\stackrel{T}{2}$ ing an early warning sign of a potentially devastating condition was very real and disconcerting to us.

We feel that our patients deserve a physician who has all the available information. Blinding the physician for research purposes diminishes the ability to make the best medical judgments on our patients $\frac{}{\bar{c}}$ behalf. Mrs W's case demonstrates that the role of physician and clinical investigator can pose a conflice and when that occurs the principle of primun nonis nocere can be unduly stressed.

Scott Groudine, MD, is Assistant Professor of Anesthesiology and Surgery, Albany Medical College $\sqrt{3}$ Albany, New York, USA. Philip D Lumb, MBBS, iș Professor and Chairman of Anesthesiology at the sames college.

\section{News and notes}

\section{Journal of Medical Ethics - http://www.jmedethics.com}

Visitors to the world wide web can now access the Fournal of Medical Ethics either through the BMJ Publishing Group's home page (http://www.bmjpg.com) or directly by using its individual URL (http://www.jmedethics.com). There they will find the following:

- Current contents list for the journal

- Contents lists of previous issues

- Members of the editorial board

- Subscribers' information

- Instructions for authors

- Details of reprint services.
A hotlink gives access to:

- BMJ Publishing Group home page

- British Medical Association website

- Online books catalogue

- BMJ Publishing Group books

The web site is at a preliminary stage and there are plans to develop it into a more sophisticated site. Suggestions from visitors about features they would like to see are welcomed. They can be left via the opening page of the BMJ Publishing Group site or, alternatively, via the journal page, through "about this site". 